\title{
Application of Biotechnology to Improve Biological Activity of Rosmarinus Officinalis Oil
}

${ }^{1}$ Soil Microbiology Unit, Desert Research Center, Cairo, Egypt

\author{
${ }^{2}$ Microbiology Dept., Faculty of Science, Benha Univ., Benha, Egypt
}

E-Mail: tameremam7@gmail.com

\begin{abstract}
Volatile oils obtained from Rosmarinus officinalis plants treated with recommended doses of organic and mineral fertilizers (VO1); plants treated with organic, mineral and bio fertilizers (VO2); plants treated with combination of organic, mineral, bio fertilizers and Biomagic (VO3) were analyzed by Gas chromatography (GC), it was illustrated that VO3 was better than VO1 and VO2 concerning known chemical constituents. Moreover, VO1, VO2 and VO3 were screened for their antibacterial, antioxidant, antitumor and antidiabetic activities. VO3 were more effective in inhibiting the growth of tested bacteria whereas VO1 was the least inhibitive. On the other hand the antitumor results revealed that VO3 exhibited the lowest inhibitory concentration 50 (IC 50 ) against MCF-7 carcinoma cell line in comparison to the other oils. The three oils were analyzed for their antioxidant activities using 2,2-Diphenyl-1-Picrylhydrazyl (DPPH\%) scavenging activity method. VO3 revealed the highest DPPH scavenging \% in comparison to the other oils. The results showed that alpha glucosidase diabetes enzyme was inhibited by all the tested oils in dose dependent manner but with superiority to VO3. This study showed great prospects in effectiveness of biofertilizers in combination with Biomagic on constituents of $R$. officinalis oil and subsequently on its biological activities. Thus, this study points to investigate the combination of biofertilizers and Biomagic as a potential tool to improve biological activities of plant volatile oils.
\end{abstract}

Keywords: Rosmarinus officinalis oils, GC, Biotechnology, Antibacterial, Antitumor, Antioxidant, Antidiabetic.

\section{Introduction}

The growing trend of antimicrobial drug resistance in virtually all organisms responsible for hospital acquired infections has become a major public health concern worldwide, due to their rapidly evolving adaptive strategies. Microorganisms have been known to successfully flourish in hospitals and community settings [1].

Antioxidants are man-made or natural substances that may prevent or delay some types of cell damage [2]. Free radicals can cause "oxidative stress," a process that can trigger cell damage.

Oxidative stress is thought to play a role in a variety of diseases including cancer, cardiovascular diseases, diabetes, Alzheimer's disease, Parkinson's disease, and eye diseases such as cataracts and age-related macular degeneration [3].

One in four deaths in the world is due to cancer. When ranked within age groups, cancer is one of the five leading causes of death amongst both males and females and the single largest cause of death worldwide [4] .

By 2015 cancer morbidity may climb to around nine million world-wide. This growing trend indicates a deficiency in the present cancer therapies which include surgical operation, radiotherapy and chemotherapy.

Since the average survival rates have remained essentially unchanged despite such aggressive treatments, there is a critical need for anti-cancer agents with higher efficacy, and less side effects that can be acquired at an affordable cost [5].

Diabetes that is a most dreadful disease affecting more than 250 million people around the world have diabetes. This total is expected to rise to 380 million within 20 years. Each year a further 7 million people develop diabetes. Long term diabetes leads to other complications like retinopathy, diabetic nephropathy, diabetic neuropathy, atherosclerosis, colon cancer etc.[6].

Type II diabetes is characterized by hepatic and peripheral (muscle and adipose tissue) insulin resistance.
The pancreas compensates by secreting more insulin, but eventually the beta cells will fail to sustain this [7], at which stage the patient requires insulin treatment. During the stage when insulin is still produced, various other classes of drugs, in combination with lifestyle alterations, can be used to manage the disease [8].

The significance of natural products in the drug discovery and development processes has been reported extensively [9].

The importance of natural products as sources of innovative therapeutic agents can be illustrated by the drugs used in the control of infectious diseases, cancer, lipid disorders, immune modulation and hypertensive diseases [10].

Rosmarinus officinalis, commonly known as Rosemary, is an evergreen perennial shrub belonging to the Lamiaceae family [11]. Native to the Mediterranean region, Rosemary is now cultivated around the world due to its use as a natural food preservative and flavoring agent [12].

Rosemary has also been used as a source of traditional medicine for centuries. Its applications have ranged from memory enhancement to the treatment of gastrointestinal diseases [13, 14].

The secret behind the preservative and therapeutic abilities of rosemary lies in its essential oil and extract. While the chemical composition of these secondary metabolites varies considerably depending on ecological conditions, all rosemary essential oils and extracts contain biologically active compounds that make them unique [15].

R. officinalis have strong antioxidant compounds in its essential oil and extract that is making $R$. officinalis a plant of great interest in today's food and medical industries [16].

Many studies have reported on the anticancer mechanisms of Rosmarinus officinalis, Rosemary has displayed significant anti proliferative activities against several human cancer cell lines [17]. 
Antidiabetic activities of $R$. officinalis oil inhibited lipid peroxidation and activated antioxidant enzymes, the oil also promoted insulin secretion [18].

The present work aimed to investigate the effect of using a combination of bacterial and fungal biofertilizers, namely; Azotobacter chroococcum and Vesicular Arbuscular Mycorrhiza (VAM) as well as addition of non-hormonal growth promoter (Biomagic) on Rosmarinus officinalis oil components and subsequently on its biological activities.

\section{Materials and methods}

2.1 Extraction of essential oils from different treatedR. officinalis plants

The plant material of Rosmarinus officinalis treated with recommended doses of mineral + organic fertilizers (group 1); plants treated with mineral + organic + bio fertilizers, (namely; Azotobacter chroococcum and VAM) (group 2); plants treated with mineral + organic + bio fertilizers and the Biomagic (microbial non-hormonal foliar spray) (group 3) were cut into pieces $(100 \mathrm{~g})$ and put separately in flasks containing double distilled water.

A continuous steam distillation extraction head was attached to the flask, after steam distillation, the oils were collected and dried over anhydrous sodium sulfate [19].

\subsection{Analysis of essential oils}

The analysis of the essential oils was performed using GC-MS (type Hewlett Packard 5890 USA). The components were identified based on the comparison of their relative retention time and mass spectra with those of standards, NBS75K library data of the GC-MS system and literature data.

The results were also confirmed by the comparison of the compounds elution order with their relative retention indices on non-polar phases reported in the literature [20].

\subsection{Antimicrobial activity of different R.officinalis oils 2.3.1 Bacterial species}

A total of eight bacterial type strains; namely Staphylococcus aureus (ATCC 6538), Staphylococcus epidermidis (ATCC 12228), Enterococcus faecalis (ATCC 29212), Proteus mirabilis (ATCC 12453), Proteus vulgaris (ATCC 8427), Klebsiella pneumoniae (ATCC 13883), Pseudomonas aeruginosa (ATCC 27853) and Salmonella typhimurium (ATCC 14028) obtained from American Type Culture Collection (ATCC) were used in the present study.

Each strain was immediately cultured on MuellerHinton agar (Bio-rad, France) for $24 \mathrm{~h}$ at $37^{\circ} \mathrm{C}$.

\subsubsection{Disc-diffusion assay}

Antibacterial tests were carried out by disc diffusion method as demonstrated by [21] using $100 \mu \mathrm{l}$ of suspension containing $10^{6} \mathrm{cfu} / \mathrm{ml}$ of tested bacteria spread on Mueller- Hinton agar medium (Bio-rad, France).

The discs $(6 \mathrm{~mm}$ in diameter) were impregnated with $20 \mu \mathrm{l}$ of oil/disc) placed on the inoculated agar. Ciprofloxacin $(20 \mu \mathrm{g} / \mathrm{disc}$ was used as a positive reference standard). The inoculated plates were incubated at $37^{\circ} \mathrm{C}$.

Antibacterial activity was evaluated by measuring the zone of inhibition against tested bacteria after 24 hours of incubation. Each assay in this experiment was carried out in triplicate.

\subsubsection{Minimum Inhibitory Concentration (MIC)}

Minimum Inhibitory Concentration values of tested essential oils were determined using two-fold serial dilutions of essential oils by the agar dilution method as described previously by [22].

MIC values were determined as the lowest concentration of tested oils where absence of growth was recorded. Each test was repeated at least twice.

\subsection{Antioxidant Assay}

The antioxidant activity of oils was determined by the DPPH free radical scavenging assay in triplicate and average values were considered.

\subsubsection{DPPH Radical Scavenging Activity}

Freshly prepared $(0.004 \%$ w/v) methanol solution of 2,2-diphenyl-1-picrylhydrazyl (DPPH) radical was prepared and stored at $10^{\circ} \mathrm{C}$ in the dark.

A methanol solution of the test compound was prepared. A $40 \mu \mathrm{L}$ aliquot of the methanol solution was added to $3 \mathrm{ml}$ of DPPH solution.

Absorbance measurements were recorded immediately with a UV-visible spectrophotometer (Milton Roy, Spectronic 1201).

The decrease in absorbance at $515 \mathrm{~nm}$ was determined continuously, with data being recorded at 1 min intervals until the absorbance stabilized (16 $\mathrm{min}$ ). The absorbance of the DPPH radical without antioxidant (control) and the reference compound ascorbic acid were also measured.

All the determinations were performed in three replicates and averaged. The percentage inhibition (PI) of the DPPH radical was calculated according to the formula: $\mathrm{PI}=(\{(A \mathrm{C}-A \mathrm{~T}) / A C\} \times 100](1) ;$ Where $A \mathrm{C}=$ Absorbance of the control at $\mathrm{t}=0 \mathrm{~min}$ and $A \mathrm{~T}=$ absorbance of the sample+DPPH at $\mathrm{t}=16 \mathrm{~min}$ [23].

\subsection{Evaluation of cytotoxic effects of different $R$. officinalis oils}

2.5.1 Mammalian cell lines MCF-7 cells

Human breast cancer cell line (MCF-7) was obtained from VACSERA Tissue Culture Unit.

\subsubsection{Chemicals used}

Dimethyl sulfoxide (DMSO), crystal violet and trypan blue dye were purchased from Sigma (St. Louis, Mo., USA). Fetal Bovine serum, DMEM, RPMI-1640, HEPES buffer solution, L-glutamine, gentamycin and $0.25 \%$ Trypsin-EDTA were purchased from Lonza.

\subsubsection{Crystal violet stain (1\%)}

It composed of $0.5 \%(\mathrm{w} / \mathrm{v})$ crystal violet and $50 \%$ methanol then made up to volume with $\mathrm{ddH}_{2} \mathrm{O}$ and filtered through a Whatmann No.1 filter paper. 


\subsubsection{Cell line Propagation}

The cells were propagated in Dulbecco's modified Eagle's medium (DMEM) supplemented with 10\% heatinactivated fetal bovine serum, 1\% L-glutamine, HEPES buffer and $50 \mu \mathrm{g} / \mathrm{ml}$ gentamycin.

All cells were maintained at $37^{\circ} \mathrm{C}$ in a humidified atmosphere with $5 \% \mathrm{CO}_{2}$ and were subcultured two times a week.

\subsubsection{Cytotoxicity evaluation using viability assay}

For cytotoxicity assay as demonstrated by [24, 25], the cells were seeded in 96-well plate at a cell concentration of $1 \times 10^{4}$ cells per well in $100 \mu$ l of growth medium.

Fresh medium containing different concentrations of the test sample was added after $24 \mathrm{~h}$ of seeding.

Serial two-fold dilutions of the tested chemical compound were added to confluent cell monolayers dispensed into 96-well, flat-bottomed microtiter plates (Falcon, NJ, USA) using a multichannel pipette.

The microtiter plates were incubated at $37^{\circ} \mathrm{C}$ in a humidified incubator with $5 \% \mathrm{CO}_{2}$ for a period of $48 \mathrm{~h}$. Three wells were used for each concentration of the test sample.

Control cells were incubated without test sample and with or without DMSO. The little percentage of DMSO present in the wells (maximal $0.1 \%$ ) was found not to affect the experiment. After incubation of the cells for at $37^{\circ} \mathrm{C}$, various concentrations of oils were added, and the incubation was continued for $24 \mathrm{~h}$ and viable cells yield was determined by a colorimetric method.

In brief, after the end of the incubation period, media were aspirated and the crystal violet solution (1\%) was added to each well for at least 30 minutes.

The stain was removed and the plates were rinsed using tap water until all excess stain is removed. Glacial acetic acid (30\%) was then added to all wells and mixed thoroughly, and then the absorbance of the plates were measured after gently shaken on Microplate reader (TECAN, Inc.), using a test wavelength of $490 \mathrm{~nm}$.

All results were corrected for background absorbance detected in wells without added stain.

Treated samples were compared with the cell control in the absence of the tested compounds.

All experiments were carried out in triplicate. The cell cytotoxic effect of each tested compound was calculated.

The optical density was measured with the microplate reader (SunRise, TECAN, Inc, USA) to determine the number of viable cells and the percentage of viability was calculated as [1-ODt/ODc)]x $100 \%$ where ODt is the mean optical density of wells treated with the tested sample and ODc is the mean optical density of untreated cells.

The relation between surviving cells and drug concentration is plotted to get the survival curve of each tumor cell line after treatment with the specified compound.

The $50 \%$ inhibitory concentration $\left(\mathrm{IC}_{50}\right)$, the concentration required to cause toxic effects in $50 \%$ of intact cells, was estimated from graphic plots of the dose response curve for each conc. using Graphpad Prism software (San Diego, CA. USA).

\subsection{In-vitro antidiabetic Assay}

$\alpha$-glucosidase (Saccharomyces cerevisiae) and 3, 5, dinitro salicylic acid (DNS) were purchased from SigmaAldrich, Bangalore. P-nitro-phenyl- $\alpha$-D-glucopyranoside (p-NPG), sodium carbonate $\left(\mathrm{Na}_{2} \mathrm{CO}_{3}\right)$, sodium dihydrogen phosphate, di-sodium hydrogen phosphate were purchased from Hi-Media, Mumbai.

$\alpha$-glucosidase inhibitory activity of different oils was carried out according to the standard method with minor modification [26].

In a 96-well plate, reaction mixture containing $50 \mu \mathrm{l}$ phosphate buffer $(100 \mathrm{mM}, \mathrm{pH}=6.8), 10 \mu \mathrm{l}$ alphaglucosidase $(1 \mathrm{U} / \mathrm{ml})$, and $20 \mu \mathrm{l}$ of varying concentrations of extracts and fractions (1000 to $7.81 \mu \mathrm{l} / \mathrm{mL})$ was pre incubated at $37^{\circ} \mathrm{C}$ for $15 \mathrm{~min}$.

Then, $20 \mu \mathrm{l}$ P-NPG $(5 \mathrm{mM})$ was added as a substrate and incubated further at $37^{\circ} \mathrm{C}$ for $20 \mathrm{~min}$. The reaction was stopped by adding $50 \mu 1 \mathrm{Na}_{2} \mathrm{CO}_{3}(0.1 \mathrm{M})$.

The absorbance of the released p-nitrophenol was measured at $405 \mathrm{~nm}$ using Multiplate Reader. Acarbose at various concentrations 1000 to $7.81 \mu \mathrm{g} / \mathrm{ml}$ ) was included as a standard.

Without test substance was set up in parallel as a control and each experiment was performed in triplicates.

The results were expressed as percentage inhibition, which was calculated using the formula, Inhibitory activity $(\%)=(1-$ As/Ac $) \times 100$, where, As is the absorbance in the presence of test substance and Ac is the absorbance of control.

\section{Results}

\subsection{Oil constituents of different rosemary oils}

The results of the chemical analyses of the different rosemary essential oils under study are presented in Table (1).

There were variations in the percentage of constituents of the three oils. Rosmarinic acid was the most abundant component in the three oil $(31.06,36.55$ and $38.67 \%)$ for VO1, VO2 and VO3 respectively.

\subsection{In vitro antibacterial activity of different rosemary oils}

The results of antibacterial activity of tested essential oils are presented in Table (2).

The three tested oils revealed antibacterial activity in concentration of $20 \mu \mathrm{l} / \mathrm{ml}$. The essential oil VO1 exhibited the lowest inhibition zone with range (12.2-17.6 $\mathrm{mm})$; while inhibition zones obtained for $\mathrm{VO} 2$ ranged from (13.3-21.9 mm). VO3 showed the highest inhibition zone range (15.4-22.3 $\mathrm{mm})$.

Interestingly, VO3 possessed a higher antibacterial effect than Ciprofloxacin against Klebsiella pneumoniae.

VO1, VO2 and VO3 revealed MIC ranges (15.63-125), (1.95-62.5) and (0.98-31.25) $\mu \mathrm{l} / \mathrm{ml}$ respectively Table (3). 
Table (1) Percentages of volatile oil components of different rosemary oils.

\begin{tabular}{|c|c|c|c|c|c|}
\hline Oil constituents & Structure & ${ }^{*} \mathbf{R T}$ & VO1 & * VO2 & *VO3 \\
\hline$\alpha$-Pinene & & 6.32 & 2.14 & 2.31 & 3.17 \\
\hline Camphor & & 10.92 & 5.90 & 7.47 & 8.56 \\
\hline$\beta$-Pinene & & 11.34 & 1.38 & 2.18 & 2.15 \\
\hline 1,8 Cineole & & 14.77 & 12.61 & 14.83 & 15.90 \\
\hline Linalool & & 15.32 & 11.41 & 12.77 & 16.11 \\
\hline Limonene & & 16.34 & 3.67 & 4.48 & 6.08 \\
\hline Terpineol & & 17.32 & 3.18 & 2.22 & 3.13 \\
\hline Borneol & & 17.96 & 5.91 & 4.23 & 3.18 \\
\hline Bornyl acetate & & 18.32 & 8.86 & 1.60 & 2.25 \\
\hline Y- Terpinene & $\therefore$ & 18.99 & 6.90 & 5.17 & 0.47 \\
\hline Eugenol & & 19.1 & 3.98 & 2.35 & 0.31 \\
\hline Rosmarinic acid & & 19.8 & 31.06 & 36.55 & 38.67 \\
\hline $\begin{array}{l}\text { Total } \\
\text { Components } \\
\text { Unknown }\end{array}$ & & & 97.00 & 96.16 & 99.97 \\
\hline
\end{tabular}

*RT: Retention Time.

Table (2) In vitro antimicrobial activities of rosemary oil tested at $20 \mu 1 / \mathrm{ml}$ and expressed as inhibition zone diameter $(\mathrm{mm})$ in the form of mean \pm SD.

\begin{tabular}{|c|c|c|c|c|}
\hline Extract code & VO1 & VO2 & VO3 & $\begin{array}{l}\text { Ciprofloxac } \\
\text { in }\end{array}$ \\
\hline Gram Positive Bacteria & \multicolumn{3}{|c|}{ Mean of inhibition zone $(\mathrm{mm}) \pm$ SD } & \\
\hline $\begin{array}{l}\text { Staphylococcus aureus }(* * A T C C \\
6538)\end{array}$ & $13.6 \pm 0.58$ & $13.9 \pm 0.58$ & $17.3 \pm 0.58$ & $21.45 \pm 1.2$ \\
\hline $\begin{array}{l}\text { Staphylococcus epidermidis (ATCC } \\
\text { 12228) }\end{array}$ & $15.4 \pm 0.63$ & $16.1 \pm 0.63$ & $\begin{array}{c}19.32 \pm \\
0.63\end{array}$ & $22.8 \pm 0.72$ \\
\hline $\begin{array}{l}\text { Enterococcus faecalis (ATCC 29212) } \\
\text { Gram negative Bacteria }\end{array}$ & $12.2 \pm 1.2$ & $13.3 \pm 1.2$ & $15.4 \pm 1.2$ & $19.3 \pm 1.5$ \\
\hline Proteus mirabilis (ATCC 12453) & $13.5 \pm 1.5$ & $15.2 \pm 1.5$ & $18.3 \pm 1.5$ & $21.2 \pm 1.2$ \\
\hline Proteus vulgaris (ATCC 8427) & $* N I Z$ & NIZ & $10.3 \pm 1.3$ & $20.4 \pm 0.63$ \\
\hline Klebsiella pneumoniae (ATCC 13883) & $16.2 \pm 0.63$ & $21.9 \pm 0.63$ & $23.1 \pm 0.63$ & $21.35 \pm 1.5$ \\
\hline $\begin{array}{l}\text { Pseudomonas aeruginosa (ATCC } \\
\text { 27853) }\end{array}$ & $17.6 \pm 0.58$ & $19.8 \pm 0.58$ & $22.3 \pm 0.58$ & $19.8 \pm 2.1$ \\
\hline $\begin{array}{l}\text { Salmonella typhimurium (ATCC } \\
\text { 14028) }\end{array}$ & $15.6 \pm 1.2$ & $17.2 \pm 1.2$ & $19.2 \pm 1.2$ & $24.8 \pm 1.5$ \\
\hline
\end{tabular}


**ATCC : American Type Culture Collection

Table (3) In vitro antibacterial activities as MICS $(\mu \mathrm{g} / \mathrm{ml})$ of different rosemary oils against tested microorganisms.

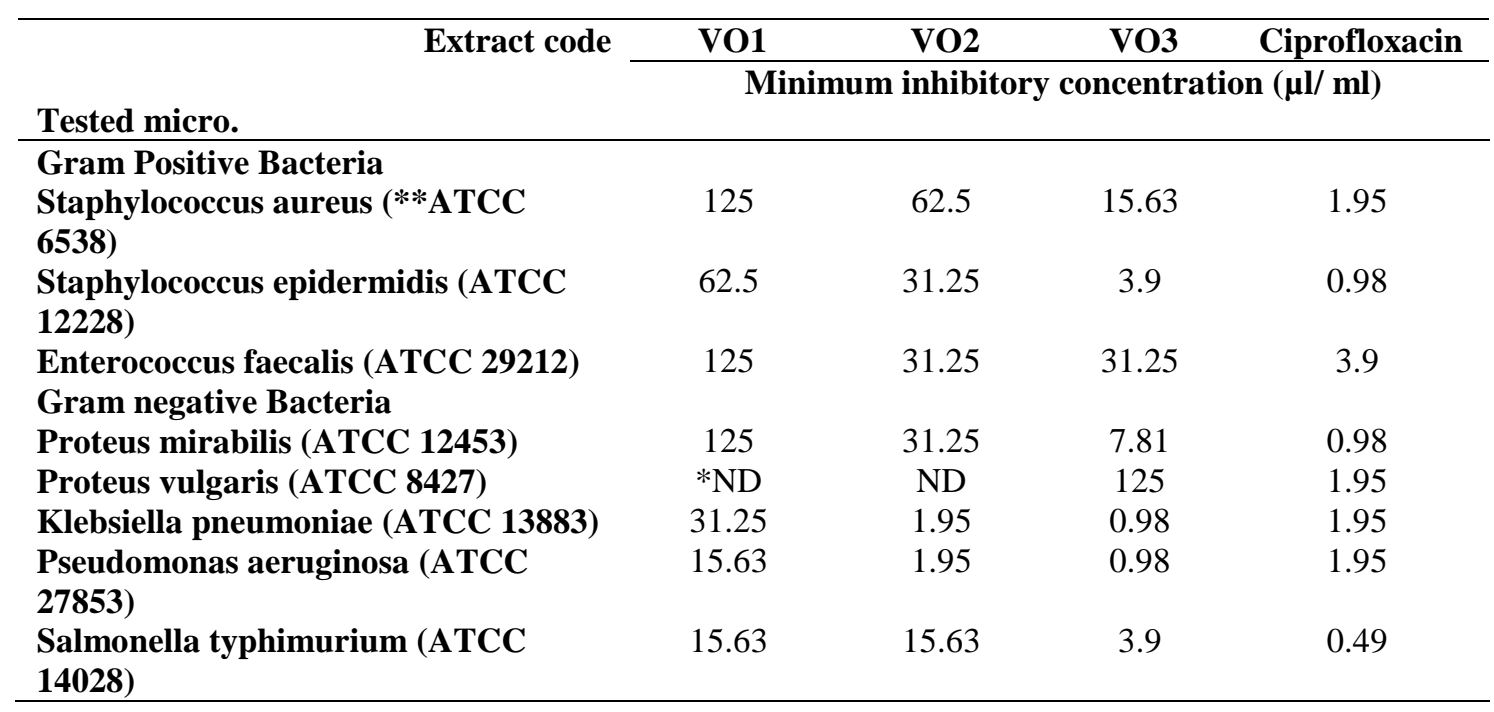

*ND: Not Detected

**ATCC : American Type Culture Collection

\subsection{In vitro antioxidant activity of different rosemary} oils

In this study, the level of antioxidants activity of volatile oils was evaluated using percentage of DPPH scavenging. Results in Fig (1a) revealed that the percentage of DPPH radical scavenging followed a concentration dependent manner.

The results indicated that the VO3 gave the highest percentage range of DPPH radical scavenging (2.10 $89.68 \%$ ). The $\mathrm{ICs}_{50}$ of oil antioxidant activity were 65.45 , $55.81,33.82$ and $29.22 \mu \mathrm{l} / \mathrm{ml}$ for $\mathrm{VO} 1, \mathrm{VO} 2, \mathrm{VO} 3$ and ascorbic acid respectively Fig (1b).

3.4 In vitro antitumor activity of different rosemary

oils

The cytotoxic activity of $\mathrm{VO} 1, \mathrm{VO} 2$ and $\mathrm{VO} 3$ were examined against MCF-7 at different concentrations. The results of the three oils showed various inhibitory effects in a dose dependent manner against breast carcinoma cell
Fig (2a). The highest inhibitory effect was detected for VO3 against MCF-7 cell line with cancer inhibitory range of $8.42-92.45 \%$, followed by VO2, while VO1 exhibited the lowest cancer inhibitory range. The lowest $\mathrm{IC}_{50}$ value was detected for VO3 $(54.24 \mu \mathrm{l} / \mathrm{ml}$ against MCF-7 Fig (2b).

\subsection{In vitro antidiabetic activity of different rosemary oils}

The maximum inhibitory percentage against $\alpha$ glucosidase was detected for VO1, VO2 and VO3 as 54.87, 62.14 and 86.32 at concentration $1 \mathrm{mg} / \mathrm{ml}$ Fig (3a).

While the descending trend of $\mathrm{IC}_{50}$ antidiabetic activity was $\mathrm{VO} 1>\mathrm{VO} 2>\mathrm{VO} 3$, the $\mathrm{ICs}_{50}$ values were detected as $385.1,115.34,51.92$ and $30.59 \mu \mathrm{l} / \mathrm{ml}$ for VO1, VO2, VO3 and acarbose, respectively as illustrated in Fig (3b)

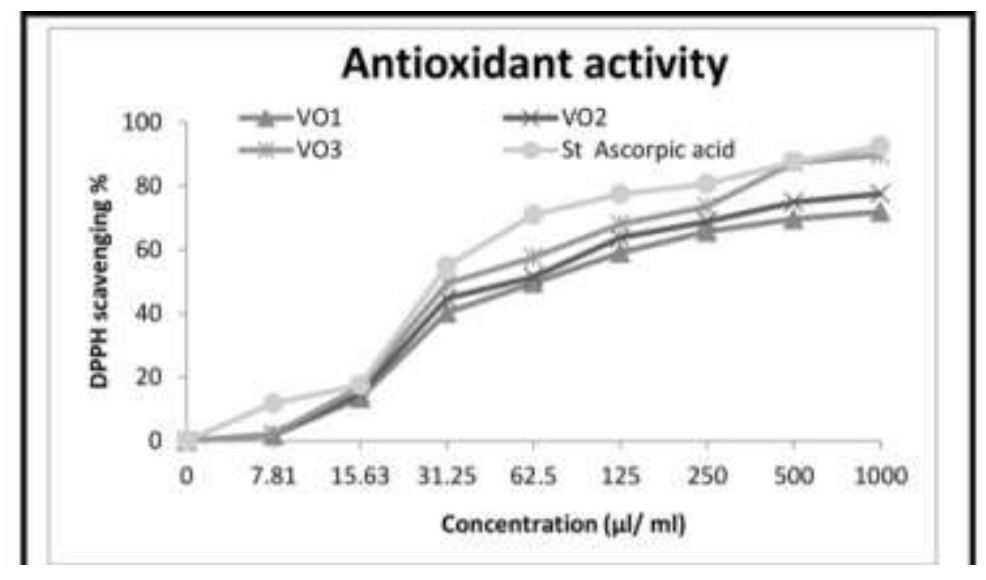

Fig (1a) The in vitro antioxidant activity of different rosemary oil 


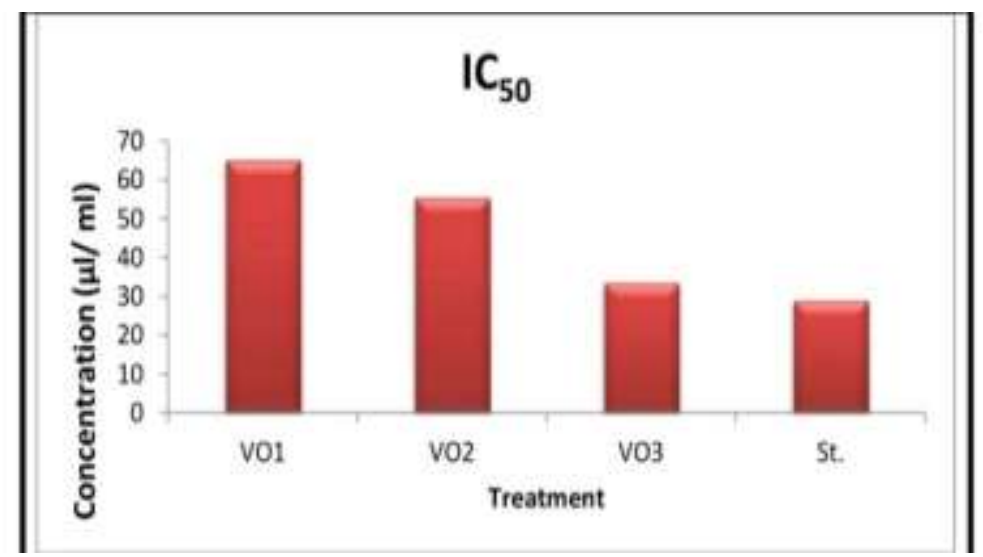

Fig (1b) The $\mathrm{IC}_{50}$ values of different rosemary oil

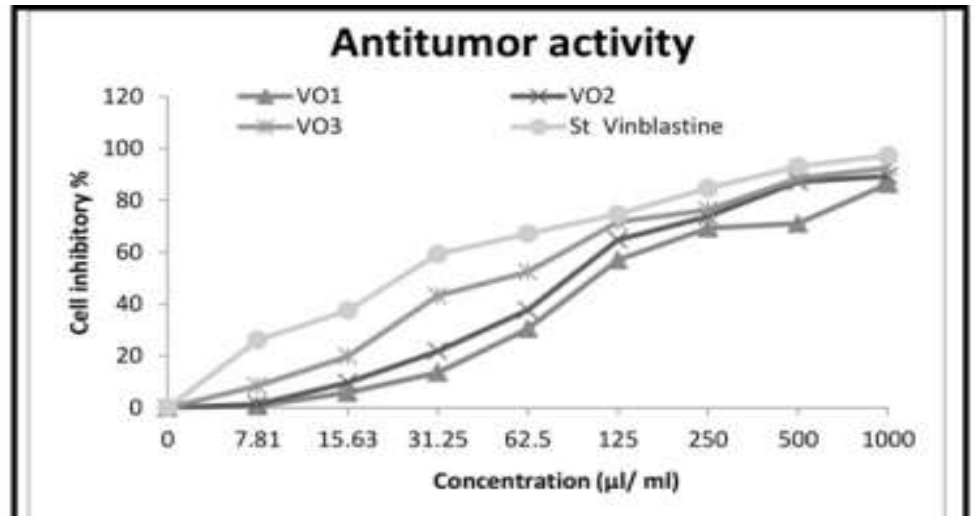

Fig (2a) The in vitro antitumor activity of different rosemary oil

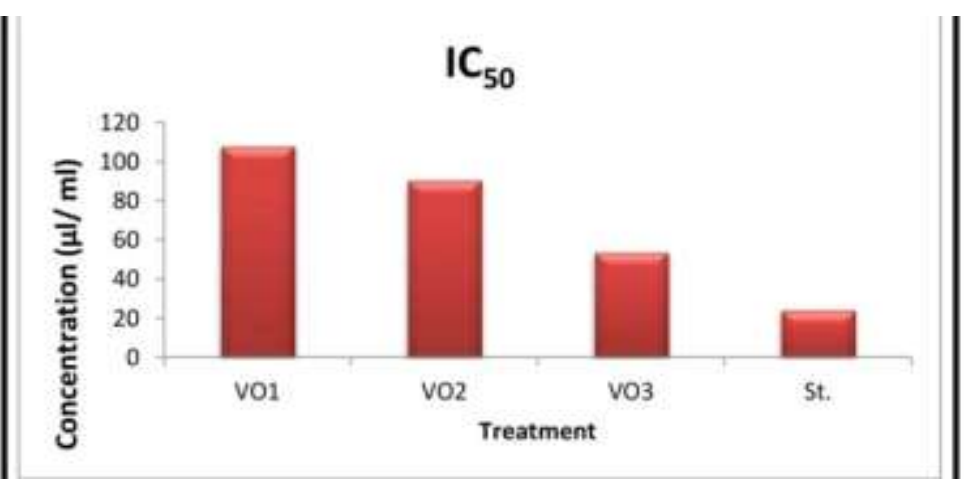

Fig (2b) The $\mathrm{IC}_{50}$ values of different rosemary oil

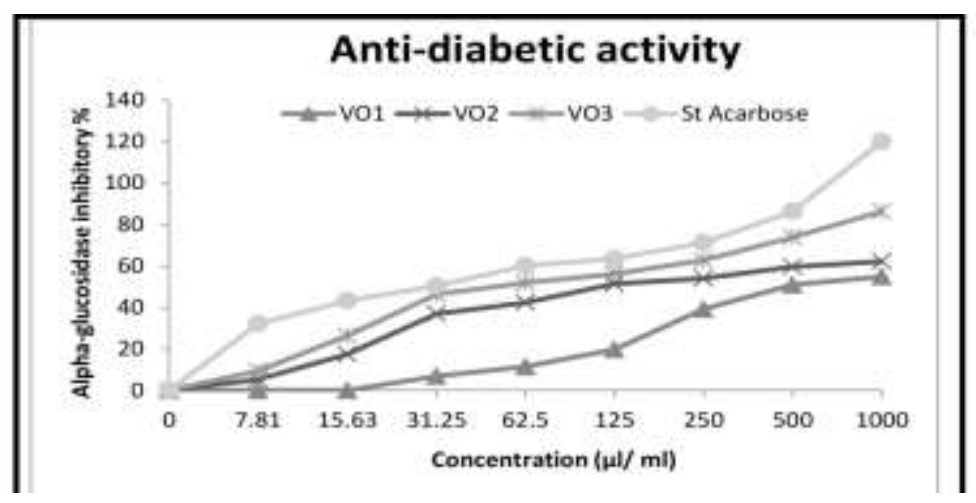

Fig (3a) The in vitro anti diabetic activity of different rosemary oil 


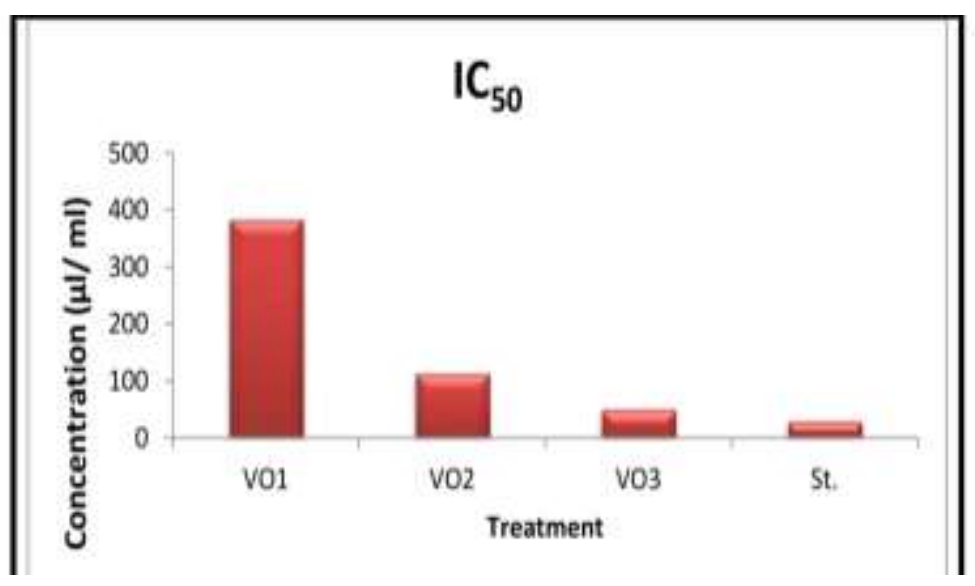

Fig (3b ) The Ic50 values of different rosemary oil

\section{Discussion}

Remarkably, Rosmarinus officinalis has displayed hepatoprotective, antispasmodic, anticarcinogenic, antitumorigenic, antimicrobial, anti-inflammatory, and antioxidant properties [27]. It has also shown antidiabetic and neuroprotective activities, among others [28]. These biological properties have made rosemary a potential new therapeutic agent in the treatment of many diseases.

In the current study GC analysis of different Rosmarinus officinalis essential oils revealed that there were variations in components percentage of the essential oil, these results agreed with previous reports on the composition of essential oil from Rosemary plant which stated that essential oil components differences according to the cultivars and fertilization [29].

Regarding the effect of fertilization treatments on volatile oil components, it could be concluded that, the maximum $\alpha$-Pinene, camphor, 1,8 cineole, linalool, limonene and rosmarinic acid content $(3.17,8.56,15.90$, $16.11,6.08$ and $38.67 \%$ respectively) were resulted in VO3 group while the lowest content of those components was recorded with VO1 group.

These results coincided with those of [30] on Thymus vulgaris who found that the application of fertiliztion increased the percentages of P-cymene, thymol and carvacrol in thyme volatile oil, [31] on Carum carvi indicated that limonene and carvone content of essential oil percentages were increased as a result of biofertilization, [32] on rosemary plants represented that application of compost with biofertilizer inoculation (namely: Azotobacter chrocooccum and Bacillus megaterium) resulted in an increment in essential oil yield and components ( 1,8-Cineol, Camphor, a Pienene, Bornyl acetate and Boreol) in comparison with the recommended dose of chemical fertilization as (control) and [33] on Lemongrass (Cymbopogon flexuosus Nees) cited that application of Humic acids with concern of plant spacing increased citral content in oil.

Rosmarinus officinalis (RA) essential oil was described to possess antimicrobial activity against wild strains of Bacillus subtilis, Micrococcus luteus and Escherichia coli [34], Pseudomonas aeruginosa,
Staphylococcus aureus, Shigella sp., and Enterobacter [35]. Further, it was reported that RA oil possessed bactericidal activity against acne causing pathogens such as S. aureus, Staphylococcus epidermidis, and Propionibacterium acne through its membrane-damaging effect [36].

In the current study the highest antibacterial activity which was obtained from VO3 may be attributed to the high content of $\alpha$-Pinene, Camphor, 1,8 Cineole and limonene, these findings in accordance with results of [37, 38], they attributed the antimicrobial property of the essential oil to the presence of $\alpha$-pinene, 1,8 cineole, camphor, verbenone and limonene.

However, they indicated that, limonene was being the most effective essential oil compound, followed by camphor and verbenone. Similarly, [39] reported that, although $\alpha$-pinene and 1, 8 cineole contents of rosemary essential oil were high, the inhibitory effect against bacteria may be related also to the content of camphor.

Interestingly, Rosmarinus officinalis essential oil is also capable of preventing lipid peroxidation, a destructive process that is caused by oxidative stress [40]. In addition to reducing the amount of reactive species in the body, rosemary has been found to increase the activity of antioxidant enzymes [41]. All these effects augment the body's defense against harmful reactive species and oxidative damage

In the present study, antioxidant activity resulted from VO3 was the highest, whilst the lowest antioxidant activity was gained from VO1, get along with this, the maximum rosmarinic acid content was acquired from VO3 treatment, at the same time the minimum rosmarinic acid content was gained from VO1, get along with this phenolic diterpenes such as rosemarinic acid had been identified as the strongest antioxidant present in rosemary essential oil [42-44].

Concerning antitumor and antidiabetic activity, the promising activity of VO3 may be attributed to the highest content of the major compound (rosmarinic acid), rosmarinic acid have been shown to induce apoptosis within these cancer cells, possibly through the production of nitric oxide [17]. Rosmarinic acid appeared to be the strongest promoter of apoptosis [45]. Rosemary extract also has intriguinganti- tumorigenic activity. Not 
surprisingly, multiple studies have identified rosmarinic acid as a promising anti diabetic agent [46-47].

Despite these encouraging findings, more research on the VO3 mechanisms of rosemary's biological activities is needed before it is consistently used to treat human disease.

\section{References}

[1] M.E.Abalaka, S.Y.Daniyan, S.O.Adeyemo and D.Damisa. The Antibacterial Efficacy of Gold Nanoparticles Derived from Gomphrena celosioides and Prunus amygdalus (Almond) Leaves on Selected Bacterial pathogens. International Scholarly and Scientific Research \& Innovation, Vol.8, PP.348-351, 2014.

[2] A.Nakayama, K.P.Alladin, O.Igbokwe and J.D. White. Systematic review: generating evidence-based guidelines on the concurrent use of dietary antioxidants and chemotherapy or radiotherapy, Cancer Investigation, Vol.29, PP.655-667, 2011.

[3] A.Jerome-Morais, A.M.Diamond, and M.E.Wright. Dietary supplements and human health: for better or for worse? Molecular Nutrition \& Food Research, Vol.55, PP.122-135, 2011.

[4] A.Jemal, R.Siegel, E.Ward, Y.Hao, J.Xu, T.Murray and M.J.Thun. Cancer statistics, CA Cancer J Clin. Vol. 58, PP.71-96, 2008.

[5] S.A.Fadey, O.O.Fadey, A.A.Adejumo, C.Okoro and E.L.Myles. In vitro anticancer screening of 24 locally used Nigerian medicinal plants. Complementary and Alternative Medicine,Vol.13, PP.79-88, 2013.

[6] P.Suryanarayana, M.Saraswati, T.Mrudula, P.Krishna, K.Krishnaswamy, and G.Reddy. Curcumin and turmeric delay streptozotocin-induced diabetic cataract in rats. Invest. Ophthalmol. OVis. Sci, Vol. 46, PP. 2092-2099, 2005.

[7] E. Cerasi. Type 2 diabetes: to stimulate or not to stimulate the cell Metabolism. Clinical and Experimental, Vol. 49, PP.1-2, 2000.

[8] S.Matthaei, M.Stumvoll, M.Kellerer, and H.Haring. Pathophysiology and pharmacological treatment of insulin resistance. Endocrine Reviews, Vol. 21, PP.585-618, 2000.

[9] F.E. Koehn, and G.T.Carter. The evolving role of natural products in drug discovery. Nature Rev Drug Discov, Vol. 4, PP. 206-220, 2005.

[10] J.Clardy and C.Walsh. Lessons from natural molecules. Nature, Vol. 432, PP.829-837, 2004.

[11] A.I.Hussain, F.Anwar, S.A.S.Chatha, A.Jabbar and S.Mahboob.Rosmarinus officinalis essential oil: antiproliferative, antioxidant and antibacterial activities. Brazilian Journal of Microbiology. Vol. 41, PP.10701078, 2010.

[12] M.B.Pérez, N.L.Calderón, and C.A.Croci. Radiation-induced enhancement of antioxidant activity in extracts of rosemary (Rosmarinus officinalis L.). Food Chemistry, Vol.104, PP.585-592, 2007.

[13] I.Orhan, S.Aslan, M.Kartal, B.Şener and K.H.C.Başer. Inhibitory effect of Turkish Rosmarinus officinalis L. on acetylcholinesterase and butyrylcholinesterase enzymes. Food Chemistry, Vol.108, PP.663-668, 2008.
[14] M.Minaiyan, A.R.Ghannadi, M.Afsharipou and P.Mahzouni. Effects of extract and essential oil of Rosmarinus officinalis L. on TNBS-induced colitis in rats. Res. Pharm. Sci, Vol.6, PP.13-21, 2011.

[15] M.J.Jordán, V.Lax, M.C.Rota, S.Lorán, and J.A.Sotomayor. Effect of bioclimatic area on the essential oil composition and antibacterial activity of Rosmarinus officinalis L. Food Control. Vol. 30, PP.463-468, 2013.

[16] R.Hamidpour, S.Hamidpour, and G.Elias. Rosmarinus Officinalis (Rosemary): a novel therapeutic agent for antioxidant, antimicrobial, anticancer, antidiabetic, antidepressant, neuroprotective, antiinflammatory, and anti-obesity treatment. Biomed $\mathbf{J}$ Sci\&Tech Res, Vol.1, PP.1- 6, 2017.

[17] S.Dilas, Z.Knez, D.Četojević-Simin, V.Tumbas, and M.Škerget. In vitro antioxidant and antiproliferative activity of three rosemary (Rosmarinus officinalis L.) extract formulations. International Journal of Food Science and Technology, Vol.47, PP.2052-2062, 2012.

[18] T.Bakirel, U.Bakirel, O.U.Keleş, S.G.Ülgen, and H.Yardibi. In vivo assessment of antidiabetic and antioxidant activities of rosemary (Rosmarinus officinalis) in alloxan-diabetic rabbits. Journal of Ethnopharmacology, Vol.116, PP.64-73, 2008.

[19] R.Farag, F.Daw, G.El-Baroty and S.Hewedi. Antimicrobial activity of some Egyptian spice essential oils. J. Food Prot, Vol.52, PP.665-667, 1989.

[20] R.Adams. Identification of essential oils components by gas Chromatography/ quadrupole mass spectroscopy. Illinois, USA: Allured Publishing Corporation, 2001.

[21] P.Murray, E.Baron, M.Pfaller, F.Tenover, and R.Yolke. Manual of clinical microbiology (6th ed.). Washington, DC: ASM, 1995.

[22] H.Gul, T.Ojanen, and O.Hanninen. Antifungal evaluation of bis Mannich bases derived from acetophenones and their corresponding piperidinols and stability studies. Biological and Pharmaceutical Bulletin, Vol.25, PP.1307-1310, 2002.

[23] G.C. Yen and P.D.Duh. Scavenging effect of methanolic extracts of peanut hulls on free radical and active oxygen species, J Agric Food Chem, Vol.42, PP.629-632, 1994.

[24] T.Mosmann. Rapid colorimetric assay for cellular growth and survival: application to proliferation and cytotoxicity assays, J. Immunol. Methods, Vol.65, PP.55-63, 1983.

[25] S.M.Gomha, S.M.Riyadh, E.A.Mahmmoud and M.M.Elaasser. Synthesis and Anticancer Activities of Thiazoles, 1,3-Thiazines, and Thiazolidine Using Chitosan-Grafted-Poly(vinylpyridine) as Basic Catalyst. Heterocycles, Vol. 91, PP.1227-1243, 2015.

[26] L.J.Shai, S.R.Magano, S.L.Lebelo, and A.M.Mogale. Inhibitory effects of five medicinal plants on rat alpha-glucosidase: Comparison with their effects on yeast alpha glucosidase. J Med Plant Res, Vol.5, PP.2863-2867, 2011.

[27] M.R.Al Sereitia, K.M.Abu Amerb and P.Sena. Pharmacology of rosemary (Rosmarinus officinalis Linn.) and its therapeutic potentials. Indian Journal of Experimental Biology, Vol.37, PP.124-131, 1999. 
[28] Z. Faixová and S. Faix. Biological effects of rosemary essential oil (A Review). Folia Veterinaria, Vol.52, PP.135-139, 2008.

[29] N.G.EL-Tantawy. Physiological effects of bio and organic fertilization on rosemary plants grown under safe agriculture conditions. M.Sc. Dept of agricultural botany, Faculty of agri., Cairo Univ., 2011.

[30] A.Ardelan K.Morteza, J.Katayoun, F.Omidreza, T.Enayatollah, and K.Ahmad. Effects of fertilizer on yield, essential oil composition, total phenolic content and antioxidant activity in Satureja hortensis L. (Lamiaceae) cultivated in Iran Journal of Medicinal Plants Research, Vol.4, PP.33-40, 2010.

[31] R.M.R. Khater. Effect of some fertilizers treatments on the growth and volatile oil yield on Carum carvi plants. M.Sc. Thesis, Fac. of Agric., Zagazig Univ., 2001.

[32] M.M.Abdelwahab. Physiological and Biotechnological Studies on Rosemary Plant in Egypt as Mediterranean Country and Indonesia as Tropical Country. M. Sc. Thesis, Fac. Agric., GadjaMada Univ., Indonesia, 2005.

[33] A.K.Tripathi, M.N.Nagrauiya, and S.P.Tiwari. Effect of fertility levels on yield of Lemon grass (Cymbopogon flexuosus Nees) under irrigated farming system Journal of Pharmacognosy and Phytochemistry; SP1. PP. 1135-1137, 2017.

[34] M.Kuhnt, A.Pröbstle, H.Rimpler, R.Bauer and M.Heinrich. Biological and pharmacological activities and further constituents of Hyptis verticillata. Planta Med. Vol. 61, PP.227-32, 1995.

[35] S.O.Salawu, A.O.Ogundare, B.B.Ola-Salawu and A.A.Akindahunsi. Antimicrobial activities of phenolic containing extract of some tropical vegetables. Afr. J. Pharm. Pharmaco. Vol.5, PP.486-92, 2011.

[36] H.U.Dong-Pei, Z.H.Jun-Ru, G.U.Yun-Zhi, X.U.Hong-Xi, and L.I.Xiao-Qian.Antibacterial and membrane - damaging activities of rosmarinic acid against pathogenic organisms of acne. Lat. Am. J. Pharm,Vol.34, PP.1866-1870, 2015.

[37] S.Prabuseenivasan, M.Jayakumar and S. Ignacimuthu. In vitro antibacterial activity of some plant essential oils. BMC Complement Altern Med, Nov 30, PP.6-39, 2006.

[38] L.Gachkar, D.Yadegari, M.B.Rezaei, M.Taghideh, S.A.Astaneh, and I. Rasooli. Chemical and biological characteristics of Cuminum cyminum and Rosmarinus essential oils. Food Chemistry, Vol.102, PP.898-904, 2007.

[39] O.Y.Celiktas, E.Bedir and F.S.Vardar. In vitro antioxidant activities of Rosmarinus officinalis extracts treated with supercritical carbon dioxide. Food Chemistry, Vol. 101, PP.1474-1481, 2007.

[40] A.Bulbul, T.Bulbul, H.Biricik, D.Yesilbag, and S.S.Gezen. Effects of various levels of rosemary and oregano volatile oil mixture on oxidative stress parameters in quails. African Journal of Biotechnology, Vol. 11, PP.1800-1805, 2012.

[41] M.S.Afonso, O.Ana Mara de Silva, B.Eliane, T.Carvalho, P.Diogo, Rivelli and B.M.Sílvia. Phenolic compounds from Rosemary (Rosmarinus officinalis L) attenuate oxidative stress and reduce blood cholesterol concentrations I diet-induced hypercholesterolemic rats. Nutrition \& Metabolism, Vol.10, PP.19-29, 2013.

[42] O.Yesil-Celiktas, P.Nartop, A.Gurel, E.Bedir, and F.Vardar Sukan. Determination of phenolic content and antioxidant activity of extracts obtained from Rosmarinus officinalis' calli. Journal of Plant Physiology, Vol.164, PP.1536-1542, 2007.

[43] S.Munné-Bosch, L.Alegre, and K.Schwarz. The formation of phenolic diterpenes in Rosmarinus officinalis L. under Mediterranean climate. Eur Food Res Tehnol, Vol.210, PP.263-267, 2010.

[44] Y.Zaouali, T.Bouzaine, and M.Boussaid. Essential oils composition in two Rosmarinus officinalis L. varieties and incidence for antimicrobial and antioxidant activities. Food and Chemical Toxicology, Vol.48, PP.3144- 3152, 2010.

[45] S.M.Petiwala, A.G.Puthenveetil, and J.J.Johnson. Polyphenols from the Mediterranean herb rosemary (Rosmarinus officinalis) for prostate cancer. Front Pharmacol, Vol.29, 2013.

[46] M.A.Abu-Al-Basal. Healing potential of Rosmarinus officinalis $\mathrm{L}$. on full-thickness excision coetaneous wounds in alloxan-diabetic BALB/c mice. Journal of Ethnopharmacology, Vol.131, PP.443-450, 2010 .

[47] O.A.Khalil, K.S.Ramadan, E.N.Danial, H.S.Alnahdi, and N.O.Ayaz. Antidiabetic activity of Rosmarinus officinalis and its relationship with the antioxidant property. African Journal of Pharmacy and Pharmacology, Vol.6, PP.1031-1036, 2012. 